OPEN ACCESS

Edited by:

Etsushi Kato,

Institute of Applied Energy, Japan

Reviewed by:

Joeri Rogeli

Imperial College London,

United Kingdom

Barry McMullin,

Dublin City University, Ireland

*Correspondence:

Andres F. Clarens

andres@virginia.edu

Specialty section:

This article was submitted to Negative Emission Technologies,

a section of the journal

Frontiers in Climate

Received: 26 August 2019 Accepted: 12 November 2019 Published: 04 December 2019

Citation:

Fuhrman J, McJeon H, Doney SC, Shobe W and Clarens AF (2019) From

Zero to Hero?: Why Integrated

Assessment Modeling of Negative

Emissions Technologies Is Hard and How We Can Do Better.

Front. Clim. 1:11.

doi: 10.3389/fclim.2019.00011

\section{From Zero to Hero?: Why Integrated Assessment Modeling of Negative Emissions Technologies Is Hard and How We Can Do Better}

\author{
Jay Fuhrman ${ }^{1}$, Haewon McJeon ${ }^{2}$, Scott C. Doney ${ }^{3}$, William Shobe ${ }^{4}$ and \\ Andres F. Clarens ${ }^{1 *}$
}

${ }^{1}$ Department of Engineering Systems and Environment, University of Virginia, Charlottesville, VA, United States, ${ }^{2}$ Joint Global Change Research Institute, University of Maryland and Pacific Northwest National Laboratory, College Park, MD, United States, ${ }^{3}$ Department of Environmental Sciences, University of Virginia, Charlottesville, VA, United States, ${ }^{4}$ Batten School of Leadership and Public Policy, University of Virginia, Charlottesville, VA, United States

Climate change mitigation strategies informed by Integrated Assessment Models (IAMs) increasingly rely on major deployments of negative emissions technologies (NETs) to achieve global climate targets. Although NETs can strongly complement emissions mitigation efforts, this dependence on the presumed future ability to deploy NETs at scale raises questions about the structural elements of IAMs that are influencing our understanding of mitigation efforts. Model inter-comparison results underpinning the IPCC's special report on Global Warming of $1.5^{\circ} \mathrm{C}$ were used to explore the role that current assumptions are having on projections and the way in which emerging technologies, economic factors, innovation, and tradeoffs between negative emissions objectives and UN Sustainable Development Goals might have on future deployment of NETs. Current generation IAM scenarios widely assume we are capable of scaling up NETs over the coming 30 years to achieve negative emissions of the same order of magnitude as current global emissions (tens of gigatons of $\mathrm{CO}_{2} /$ year) predominantly relying on highly land intensive NETs. While the technological potential of some of these approaches (e.g., direct air capture) is much greater than for the land-based technologies, these are seldom included in the scenarios. Alternative NETs (e.g., accelerated weathering) are generally excluded because of connections with industrial sectors or earth system processes that are not yet included in many models. In all cases, modeling results suggest that significant NET activity will be conducted in developing regions, raising concerns about tradeoffs with UN Sustainable Development Goals. These findings provide insight into how to improve treatment of NETs in IAMs to better inform international climate policy discussions. We emphasize the need to better understand relative strength and weaknesses of full suite of NETs that can help inform the decision making for policy makers and stakeholders.

Keywords: negative emissions technologies, integrated assessment modeling, carbon dioxide removal, sustainable development goals, climate policy 


\section{INTRODUCTION}

Efforts by the United Nations and others to develop a coordinated global response to climate change rely heavily on an ensemble of Integrated Assessment Models (IAMs) to make projections linking human activities to climate outcomes (IPCC, 2014, 2018). IAMs are coupled models of the global economic and climate systems, first developed to represent fossil fuel emissions from the energy system (Reister and Edmonds, 1977), and later expanded to include land use change and forestry emissions, as well as non- $\mathrm{CO}_{2}$ emissions (Di Vittorio et al., 2014). To limit global temperature change to 1.5 or $2^{\circ} \mathrm{C}$ within this century, as agreed upon in the Paris Agreement on Climate Change, IAM scenarios have increasingly incorporated negative emissions technologies (NETs) to achieve carbon dioxide removal (CDR) (IPCC, 2014, 2018). NETs are a broad class of large-scale, deliberate activities for removing $\mathrm{CO}_{2}$ from the atmosphere. While many negative emissions approaches are theoretically possible, few have been deployed commercially (with the exception of reforestation and forest management), and none at anywhere near the scales required to meaningfully contribute to climate mitigation (Vaughan and Gough, 2016; California Department of Forestry Fire Protection, 2018; Haszeldine et al., 2018; He and Mo, 2019).

NETs approaches can be broadly classified into surface-based processes that increase organic and inorganic carbon densities in the biosphere and soils, or deep-subsurface processes that store $\mathrm{CO}_{2}$ in geologic formations. Surface-based NETs include afforestation and reforestation (AR), coastal blue carbon (CBC), increasing soil carbon (SC) through biochar application, and accelerated weathering (AW) of silicate minerals (NRC, 2015, 2018). These surface-based NETs are generally well-understood but considered more vulnerable to future disturbance or change in practice (e.g., forest fires, land-clearing, soil loss). Subsurfacebased NETs include direct air capture (DAC) and bioenergy with carbon capture and storage (BECCS). These sub-surface based approaches are less mature than surface-based approaches but are considered to be more permanent (Matter et al., 2016). To date, IAMs have generally modeled the deployment of only BECCS and AR. Other NETs have not been considered in IAMs primarily because of connections to sectors that have not yet been included in these models, and because parameterizing these technologies is speculative given that NETs are not being deployed commercially today. A number of ocean-based approaches to remove atmospheric carbon dioxide have also been proposed over the years but those have yet to be modeled by the IAM community (Gattuso et al., 2018).

The growing interest in NETs is driven by the recognition that efforts to limit warming to 1.5 or $2^{\circ} \mathrm{C}$ without them would require emissions reductions in the coming years that are strongly at-odds with current and intended future global climate policy (Grubler et al., 2018; United Nations Environment Programme, 2018). Current deployment of climate mitigation activities that prevent $\mathrm{CO}_{2}$ from entering the atmosphere in the first place (e.g., energy conservation, renewable energy, and fossil carbon capture and storage) is encouraging but will proceed too slowly to achieve the kinds of climate stabilization goals laid out by the UN (Tollefson, 2018; Climate Action Tracker, 2019).
Using independent modeling frameworks, a number of research groups have concluded that NETs will be needed to complement conventional mitigation activities. Even though model structures differ between IAMs (e.g., computable general equilibrium vs. system dynamics), cost and resource constraints determine the balance between traditional emissions abatement options and NETs deployment-in virtually all cases NETs play a large role.

This growing reliance on NETs in IAM projections is evident in the recent IPCC Special Report on Global Warming of $1.5^{\circ} \mathrm{C}$ (IPCC, 2018). The modeling underpinning that report came from research groups from around the world using a range of different IAMs. Figure 1 presents the results from the IPPC SR1.5 Scenario Database plotted in terms of peak projected NETs deployment rates vs. the cumulative additional $\mathrm{CO}_{2}$ emissions before reaching net-zero (2016 to year of net-zero emissions) (Huppmann et al., 2018). Almost all the scenarios that were able to achieve a $1.5^{\circ} \mathrm{C}$ future (deep purple dots) deployed significant amounts of NETs. Lighter colored model outcomes deployed far less NET capacity but also project a future with cumulative warming of $4-5^{\circ} \mathrm{C}$, which would have catastrophic impacts. To provide a frame of reference for the $y$-axis, annual global $\mathrm{CO}_{2}$ emissions today are on the order of $40 \mathrm{GtCO}_{2} / \mathrm{yr}$, so the amount of NETs that these scenarios assume we would deploy is on the order of $30-50 \%$ of current emissions (Rogelj et al., in press; Clarke et al., 2014). NETs present significant tradeoffs between biogeophysical or economic outcomes that have only recently begun to be studied (Smith et al., 2016; Fuss et al., 2018; Minx et al., 2018; Nemet et al., 2018). Some NETs, such as BECCS, are land-use intensive, which will create competition with food, fuel and fiber (Kato and Yamagata, 2014). Some appear to be low-cost, such as $\mathrm{CBC}$, with significant co-benefits, while others are thought to be capital and energy intensive with unknown co-benefits, such as DAC. These tradeoffs are a challenge to model in IAMs given how little we know about how these technologies might be deployed at scale.

Most of the scenarios shown in Figure 1 were developed with the objective of finding the economically least-cost means of limiting warming to a given target by 2100 , without considering realistic scale-up rates of NETs, or trade-offs with other objectives (e.g., sustainable development goals). Those scenarios which applied additional design criteria and/or constraints to reflect these other factors generally find much lower NETs deployment and a greater emphasis on near-term mitigation (i.e., lower left corner of Figure 1). Such drastic mitigation required to limit future NETs deployment would need to be mediated by significant lifestyle changes, expansions in renewable energy and electrification, and reductions in non- $\mathrm{CO}_{2}$ GHG emissions (van Vuuren et al., 2018).

A more comprehensive handling of NETs is beginning to emerge in the climate modeling literature. Holz et al. (2018) modeled the deployment of biochar, accelerated weathering, and soil carbon management, as well as DAC, BECCS, and AR in the C-ROADS and En-ROADS system dynamics models, finding that more ambitious mitigation efforts are required for all $1.5^{\circ} \mathrm{C}$ compliant scenarios, especially those which assume limited availability of NETs in the future (Holz et al., 2018). Surface based NETs (e.g., BC, AR) have been reported to exhibit storage 


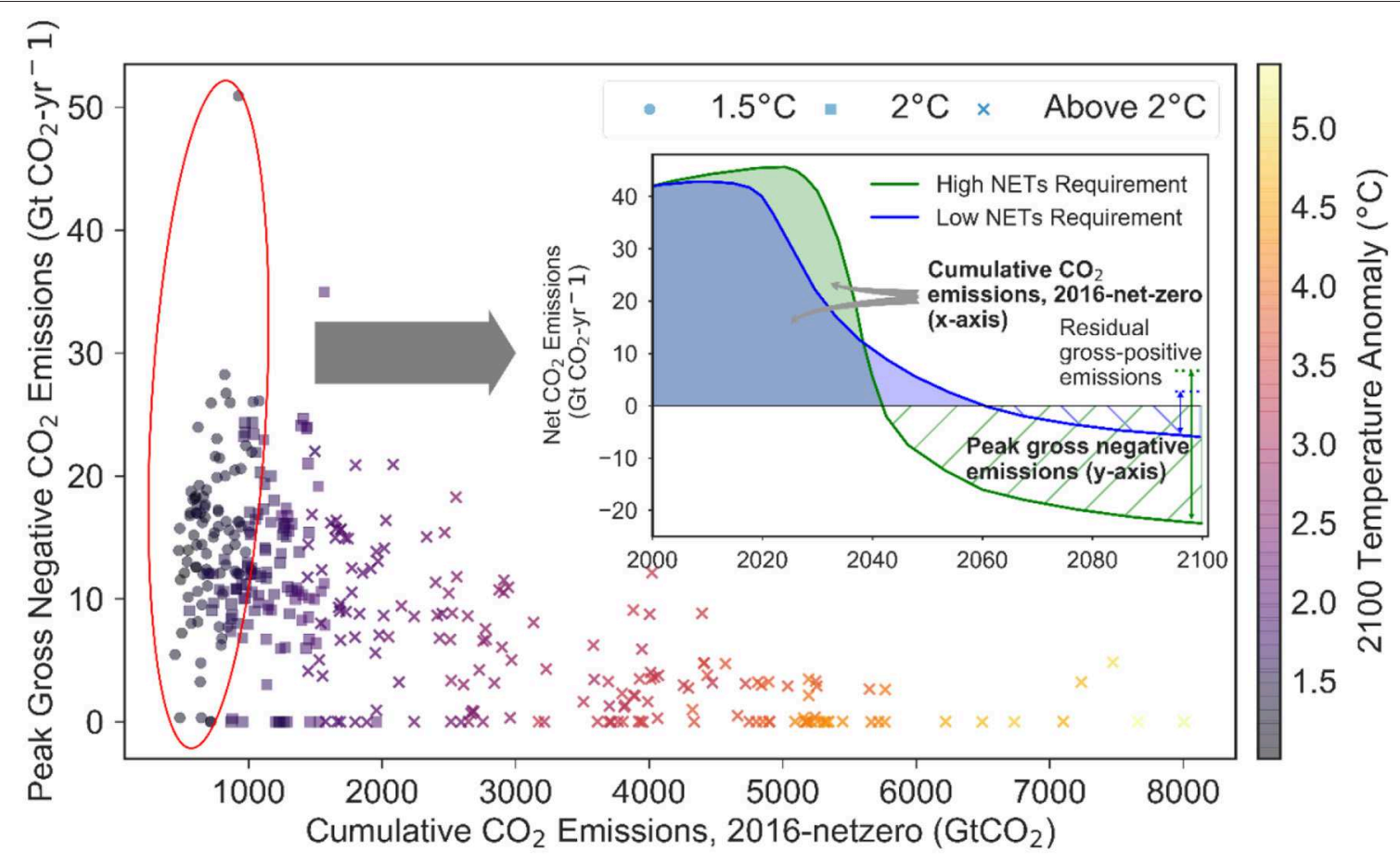

FIGURE 1 | IAM scenarios consistent with limiting end-of-century warming to $1.5^{\circ} \mathrm{C}$ (circles) or $2^{\circ} \mathrm{C}$ (squares) above preindustrial levels have exceedingly small remaining cumulative $\mathrm{CO}_{2}$ emissions budgets (from 2016 to year of net-zero emissions) and nearly all require significant future $\mathrm{CO}_{2}$ removal from the atmosphere using NETs. As illustrated in the inset, for a given temperature target (e.g., those trajectories that achieve $1.5^{\circ} \mathrm{C}$ indicated by the red circle), future NET requirements are governed both by the magnitude of the greenhouse gas pulse emitted previously, as well as by residual gross-positive emissions from those sectors of the economy which are recalcitrant to decarbonization once a climate policy is implemented (e.g., air travel). Increased cumulative emissions after 2016 before reaching net-zero generally corresponds to increased peak future NETs deployment and associated impacts. Data source: Huppmann et al. (2018) (main figure); Lawrence (2019) (inset).

losses, which in some scenarios required gross $\mathrm{CO}_{2}$ removal to be maintained simply to offset storage losses from $\mathrm{CO}_{2}$ sequestered previously in soils (Sanderman et al., 2017). Creutzig et al. compared prospective impacts of BECCS and DAC on the energy system, providing analysis of the three IAM studies incorporating both. IAM assumptions and results for BECCS energy yields per $\mathrm{tCO}_{2}$ sequestered are compared and found to differ significantly (up to $40 \%$ ) in magnitude and potentially sign direction from detailed bottom-up modeling results. The authors also find that DAC costs and energy inputs may be overstated in existing IAM studies (Creutzig et al., 2019). Modeling a broader portfolio of NETs can increase negative emissions capacity while reducing total policy cost (Nemet et al., 2018; Rau, 2018).

Because of its potential to scale, DAC is increasingly the focus of a number of studies (Realmonte et al., 2019). Chen and Tavoni (2013) studied DAC using the WITCH model and found that DAC could reduce total and marginal abatement costs, enable the postponement of mitigation activities, and prolong the use of oil, enabling energy-exporting countries to continue to sell low-carbon oil on the global market. This is found to provide a means to encourage energy-rich countries to participate in international climate agreements, as meeting aggressive targets is impossible without their involvement due to the mitigation burden on the remaining countries. Marcucci et al. (2017) used MERGE-ETL to quantify the energy transition and economic consequences of limiting global warming to 1.5 and $2^{\circ} \mathrm{C}$ by the end of the century (Marcucci et al., 2017). They report that limiting warming to $1.5^{\circ} \mathrm{C}$ is only possible with the use of DAC, which acts as a complement for BECCS. The authors note that, if the assumed learning rates for cost and efficiency of DAC are not met, its role could be substantially reduced. They call for additional analysis (e.g., Monte Carlo or other stochastic modeling) aimed at providing a sensitivity analyses (Edenhofer et al., 2018). Another recent paper used the REMIND model to evaluate tradeoffs between near-term mitigation, high transitional costs, and the need for large-scale future deployment of NETs, of which BECCS, afforestation, and DAC are available after 2030 (Edenhofer et al., 2018). Most recently, the TIAM-Grantham and WITCH IAMs models were compared to assess the impact of DAC on meeting the 1.5 and $2{ }^{\circ} \mathrm{C}$ mitigation targets, finding the potential of DAC to reduce 2030 carbon prices by up to $50 \%$, while noting that failing to meet the large projected scaleup rates of the technology could result in temperature overshoot of $0.8^{\circ} \mathrm{C}$ by 2100 (Realmonte et al., 2019).

IAM projections will undoubtedly improve as the body of literature examining NETs continues to grow. We need ground-truth data, scaling economics, time-scales and barriers as well as resource demands and trade-offs to know whether these technologies will ever play as significant of a role as today's IAMs suggest. But a much more robust and defensible treatment of NETs in the IAM simulations is possible today if the research community focuses on improving three elements 


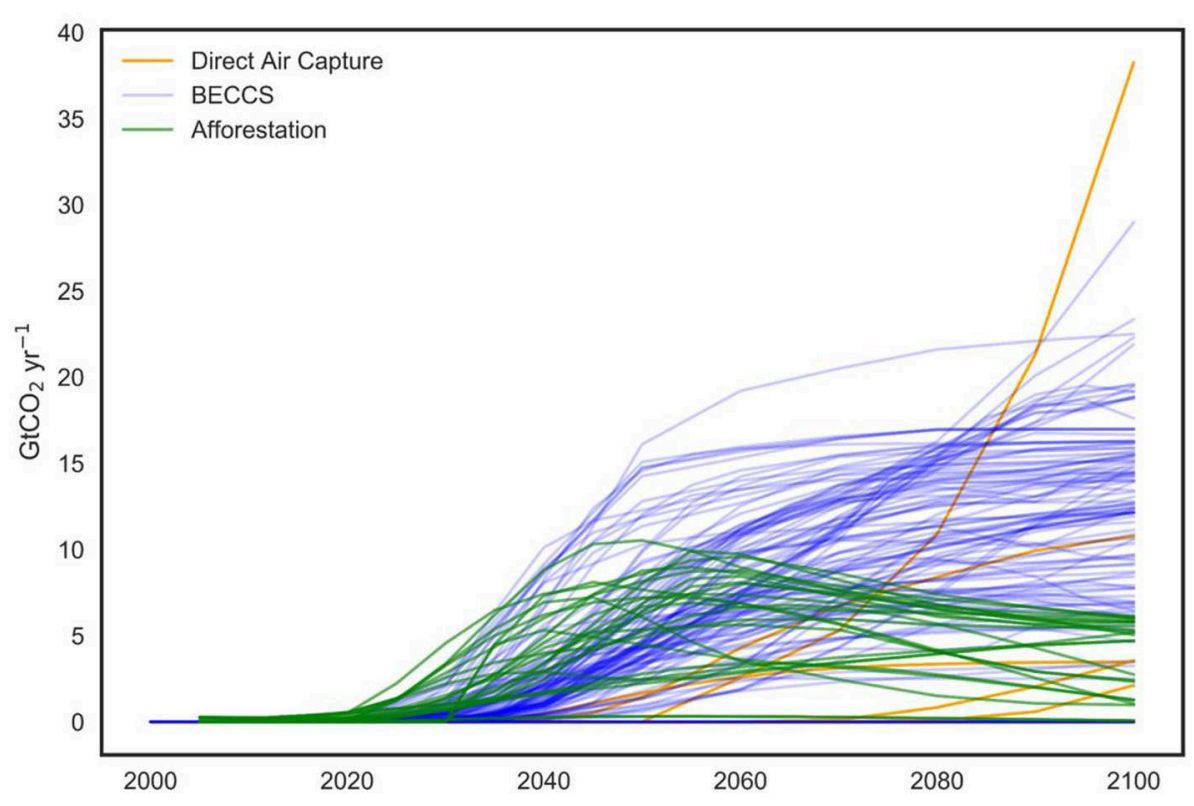

FIGURE 2 | A comparison of NETs results from several different IAMs and system-dynamics models reveal that virtually all rely primarily on BECCS to limit warming to $1.5^{\circ} \mathrm{C}$ by 2100 . These technologies are being deployed in the models at large scales even though they have not been demonstrated at commercial scale. There is an urgent need to significantly improve the way NETs are being handled by IAMs, and incorporate a broader portfolio of technologies so that scientists, engineers, policymakers, and the public are better informed for making the best decisions possible related to NET research and development. Data source: Huppmann et al. (2018).

of their modeling: (1) increasing the portfolio of technologies possible; (2) improving our handling of the economics of NETs and innovation rates; and (3) consideration of the impacts that NETs will have on sustainable development goals and equity issues between nations. Here we discuss each of these and make recommendations for the research community to address these needs.

Our analysis is framed in the context of the data that is the basis for the IPCC Special Report on Global Warming of $1.5^{\circ} \mathrm{C}$, which provides quantitative mitigation pathways for 177 scenarios generated by 25 IAM and systems dynamics model versions (some models had different versions that are accounted for in this counting) (Rogelj et al., in press; Huppmann et al., 2018). Only those modeling runs that are successful in limiting end-of-century warming to $1.5^{\circ} \mathrm{C}$, both with and without intermediary temperature overshoot, were included. Within this grouping, 90 scenarios from 13 different studies meet the criteria. The data used here is available at the IAMC Scenario Explorer Portal (Huppmann et al., 2018). The computer code used to process the data here is available in the Supporting Information and available online on GitHub.

\section{RECOMMENDATION \#1: WE NEED TO MODEL MORE TYPES OF NETS}

The vast majority of IAM simulations in the $1.5^{\circ} \mathrm{C}$ database find that NETs deployment will need to ramp up rapidly over the coming decades, mostly between 2020 and 2050, and then be sustained in order to meet climate targets (Figure 2). Almost all the modeled NETs capacity is BECCS and AR with only a small number of studies including DAC. In virtually all cases, the models assume that we can achieve rapid scale-up times and large deployments by the end of the century. Most model results show that NETs will follow a logistic growth path, where exponential growth transitions to a constant level of deployment. Other scenarios show continued exponential growth through 2100. In aggregate, these model scenarios indicate that we would deploy afforestation at an average scale of $\sim 5 \mathrm{GtCO}_{2} /$ yr (range 2-10 $\mathrm{GtCO}_{2} / \mathrm{yr}$ ) and BECCS on average $\sim 12 \mathrm{GtCO}_{2} / \mathrm{yr}$ (range $5-20 \mathrm{GtCO}_{2} / \mathrm{yr}$ ) by midcentury and continuing through 2100 . At present we are relying on reforestation for $<<1 \mathrm{GtCO}_{2} / \mathrm{yr}$ and BECCS for $0 \mathrm{GtCO}_{2} / \mathrm{yr}$, highlighting how rapidly we would need to scale up these technologies. The likely effects of these activities on fertilizer consumption, biodiversity, food prices, air quality, and water availability (to name a few) would be significant and is only beginning to be estimated.

\section{Afforestation and Reforestation}

Reforestation entails allowing previously deforested lands to revert back to their natural states, while afforestation involves the growth of new forest lands where they did not previously exist (e.g., native grasslands) (Keller et al., 2018). Both create a negative emissions pulse during the growth phase for new forests. Tradeoffs (e.g., land and water availability) between afforestation, bioenergy, and food will limit its deployment (Jobbágy and Jackson, 2004; Ornstein et al., 2009). But unlike other forms of NETs, we have empirical evidence about how 
effective afforestation activities are and this will enable us to calibrate models to provide better projections (Bastin et al., 2019).

\section{Bioenergy With Carbon Capture and Storage}

BECCS is the most widely modeled NET to date and many models suggest it would require the planting of significant areas with bioenergy crops as well as major new infrastructure development in the form of power plants (Mac Dowell and Fajardy, 2017), $\mathrm{CO}_{2}$ pipelines (Abotalib et al., 2016), and wells and monitoring equipment for geological sequestration (Muratori et al., 2016). The growth of biomass for BECCS, as well as for liquid fuels, in which the carbon is reemitted to the atmosphere upon combustion in non-point sources (e.g., transportation), result in large water and fertilizer demands.

\section{Direct Air Capture}

Even though DAC will require less water and land use per ton of $\mathrm{CO}_{2}$ captured than BECCS and AF, these impacts may still be significant and need to be quantified (Realmonte et al., 2019). DAC would account for a significant portion of global energy demand if the large deployments envisaged by some IAMs are achieved with potential environmental impacts, especially if this energy comes from fossil fuels (Howarth et al., 2011; Keith et al., 2018; Realmonte et al., 2019). DAC will entail the same issues in monitoring geologically sequestered $\mathrm{CO}_{2}$ as BECCS and post-combustion CCS of fossil fuels (Middleton et al., 2014).

\section{EMERGING NETS}

The land use requirements and other side effects of BECCS and $\mathrm{AR}$ are contributing to increasing discussion of other forms of NETs. These approaches have not generally been incorporated into IAMs more widely, and opportunities and challenges exist with modeling these approaches.

\section{Accelerated Weathering}

Accelerated weathering (AW) refers broadly to reaction of $\mathrm{CO}_{2}$ with mineral species (primarily calcium and magnesium silicates) to form thermodynamically favorable and chemically stable solid carbonates. AW can be performed on virgin feedstocks (like basalt or olivine rock) or on waste streams (alkaline streams such as steel slag) (Huijgen et al., 2005). AW is an example of a NET with large potential global capacity and co-benefits, but also significant potential side effects that have generally not yet been considered by the IAM community. Global potential for $\mathrm{AW}$ could be as high as $95 \mathrm{GtCO}_{2} / \mathrm{yr}$ for dunite, 4.9 $\mathrm{GtCO}_{2} / \mathrm{yr}$ for basalt (Strefler et al., 2018). There is a growing body of literature focused on deploying AW on croplands, which could provide co-benefits of increased yields through enhancing soil alkalinity and structure and providing beneficial use for silicate waste materials (Beerling et al., 2018). Runoff from land application could also help offset ocean acidification (Taylor et al., 2016). The best locations for terrestrial AW are in warm and humid regions offering the potential to reduce land use stress in these regions by increasing crop yields for bioenergy and food (Kohler et al., 2010). AW also has potential for codeployment with afforestation, reforestation, BECCS, biochar; capturing these interaction effects with IAMs could increase the total rate capacity of negative emissions while reducing costs (Kantola et al., 2017). However, large scale deployment also risks concentrating significant environmental costs associated with surface mining, as well as soil contamination with metals, and surface water alkalinity increases in these regions.

\section{Soil Carbon/Biochar}

While reforestation is the most widely discussed surface-based negative emissions approach, several other forest and agricultural land management practices are lower-cost $\left(<\$ 10 / \mathrm{tCO}_{2}\right)$ and also provide co-benefits in the form of improved air, water, and soil quality, and biodiversity enhancement (Griscom et al., 2017). These practices could be implemented on existing forest or agricultural lands and thus reduce land stress relative to other NETs (e.g., BECCS/AR). For forest management, accelerating regeneration of disturbed areas, extending timber rotations, and thinning to promote higher stand growth/avoid large wildfires could increase capacity of existing forest lands without significantly encroaching on other land uses. On agricultural lands, cover crops, adoption of low-till agricultural practices, conversion to perennial crops, and improved grazing land management could all result in significant atmospheric carbon removal (NRC, 2018). The combined carbon cycle and economic modeling of IAMs could allow assessment of both the direct and indirect (i.e., market-mediated) effects of such activities, although substantial parametric uncertainty could affect results. Sensitivity analysis using IAMs could help highlight uncertain parameters with a greater impact on global climate results such that research funding could be better directed at better constraining these estimates.

\section{Ocean-Based Approaches}

The ocean offers near limitless potential for negative emissions even though the costs and impacts of these approaches are only beginning to be characterized (GESAMP, 2019). Some of the research activity in this space is focused on promoting coastal ecosystems to sequester carbon in soils and sediments (Macreadie et al., 2017). IAMs could highlight the opportunities to avoid further degradation of these ecosystems as a relatively low-cost climate abatement method with significant co-benefits, including climate adaptation, clean water, and biodiversity enhancement (Furukawa et al., 1997; Gacia and Duarte, 2001; Mendez and Losada, 2004; Nagelkerken et al., 2008; Barbier et al., 2011; McLeod et al., 2011; Yang et al., 2012; Mayor's Office of Recovery Resiliency, 2019). For IAMs to capture these effects, spatially explicit datasets, as well as a more detailed understanding of carbon cycle dynamics at play in these complex ecosystems is needed (Macreadie et al., 2017).

\section{RECOMMENDATION \#2: WE NEED TO BETTER UNDERSTAND HOW THE ECONOMICS OF NETS WILL CHANGE WITH TIME AND INNOVATION}

IAMs are, at their core, economic models that make projections about technology deployments, carbon prices and emissions 


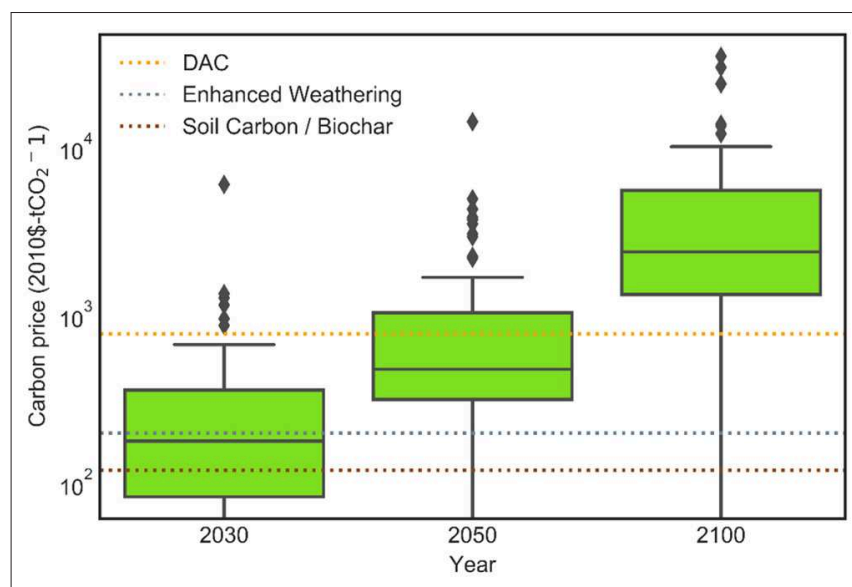

FIGURE 3 | Carbon prices for $1.5^{\circ} \mathrm{C}$ scenarios at three different time horizons relative to the upper bounds of cost estimates from Minx 2018 for NETs not yet widely incorporated into IAMs. By 2100 , most carbon prices reach well above even the most conservative estimates for DAC, which is commonly thought to be the costliest NET.

(Calvin et al., 2019). While some NETs, such as AR or CBC could achieve emissions reductions at costs $<\$ 100 / \mathrm{tCO}_{2}$ today, these costs are still higher than most voluntary markets (Nemet et al., 2018). Many of the scenarios used for the IPCC $1.5^{\circ} \mathrm{C}$ report estimate that carbon prices will exceed the costs of NETs by midcentury. This is shown for the case of DAC, commonly assumed to be one of the more expensive NETs, in Figure 3. While the costs of DAC $\left(\$ 100-600 / \mathrm{tCO}_{2}\right)$ are higher than carbon cost projections in the models today, by midcentury the average cost of carbon is near the upper bound of the DAC cost.

The extent to which IAMs rely on future negative emissions is largely a result of structural elements of the scenarios designed by modeling teams in order meet the targets set by policymakers, which generally focus on meeting specific temperature targets (e.g., 1.5 or $2^{\circ} \mathrm{C}$ ) in 2100 (Rogelj et al., 2019). With the promise of future NETs, near-term emissions can remain high, leading to elevated atmospheric $\mathrm{CO}_{2}$ levels which can be drawn down later, as long as temperature returns to "safe" levels by 2100 . This increases the likelihood that the emission path will temporarily overshoot the temperature target (Lemoine and Traeger, 2016). The incremental damage (e.g., from increased extreme weather) during temperature overshoot is not well-understood or fully taken into account by current-generation IAMs (Tavoni and Socolow, 2013). Additionally, under assumptions of increased climate sensitivity, even temporary overshoot above "safe" climate targets may have significant consequences, which even large amounts of NETs cannot reverse within decadal timescales (Steffen et al., 2018). This is made more likely by the relatively simplified climate models of IAMs, which do not capture irreversible climate feedback effects (e.g., ice sheet albedo, thawing permafrost), since later carbon removal using NETs may only partially offset warming from previous emissions (Zickfeld et al., 2016). Finally, the use of NETs will be greater than what is optimal if NETs generate uninternalized environmental costs of their own (e.g., biodiversity loss, water contamination).
IAMs were developed to help explore sensitivity to and implications of a variety of "known unknowns," including social discount rates and rates of technological change. While imperfect, they are valuable tools to assess implications and tradeoffs of meeting the aggressive targets needed to limit catastrophic climate damages. Rather than being scrapped, they should be improved and supplemented with other analytical approaches (Gambhir et al., 2019). For example, a recent model incorporating future risks and policy-induced technological change inverts the conventionally accepted price path of initiallylow and rising GHG emissions prices, to one of initially high and declining prices (Daniel et al., 2019). Scenarios which emphasize such prompt and aggressive action in order to limit peak, rather than end of century warming would necessarily rely less on future NETs deployment and be more in line with the text of the Paris Accord, as well as the precautionary principle of the UNFCCC (UNFCCC and Conference of the Parties (COP), 2015; Schleussner et al., 2016; Obersteiner et al., 2018; Rogelj et al., 2019).

All climate mitigation technologies, including NETs, have different capacities and assumed growth rates, which affect to what extent, and how quickly they are projected to be deployed in IAM scenarios. Some IAMs (e.g., GCAM, MESSAGE) parameterize technological growth exogenously, which allows sensitivity analysis of cost/efficiency targets for different technologies which can help inform R\&D investment decisions. Others (e.g., WITCH or MERGE-ETL) handle technological growth endogenously, attempting to capture responsiveness of technological change to economic incentives. Directed technological change in the context of climate change has been framed as encouraging "clean" over "dirty" technologies, which are close substitutes in producing goods. Both a price on emissions and subsidies to $\mathrm{R} \& \mathrm{D}$ are required to achieve the least cost transition from the incumbent dirty process to the innovative clean process. But NETs are fundamentally different from energy production technology because demand for CDR is induced entirely by policy rather than demand for a final consumption good. Certainly, $R \& D$ will be needed to overcome the scale barriers to these technologies, but entirely new markets will also need to be created. The scale of these markets would exceed that of some of the largest industries in existence today. For example, the median peak projected $\mathrm{CO}_{2}$ removal rate for IAM scenarios limiting end-of-century warming to $1.5 \mathrm{C}\left(\sim 15 \mathrm{GtCO}_{2}-\mathrm{yr}^{-1}\right)$ is over $200 \%$ of 2018 natural gas combustion emissions, and over $133 \%$ of the total mass of fossil fuels extracted globally (Sen and Peucker-Ehrenbrink, 2012; Le Quéré et al., 2018; BP, 2019). For reference, the fossil fuel industry is currently subsidized to the tune of $\$ 4.7$ trillion- $\mathrm{yr}^{-1}$ or $6.3 \%$ of global GDP (Coady et al., 2019). This is entirely inconsistent with climatically-meaningful emissions reductions; let alone global-scale negative emissions. However, if the "market" for NETs is established and scale economies are achieved, the policy cost of additional negative emissions will fall (Acemoglu et al., 2012, 2014).

Two important problems arise at this point. First, while it is not hard to imagine some harmonized global price on greenhouse gas emissions, it is less easy to imagine an internationally 
harmonized system for subsidizing the development of new technology. The institutional framework for the policies used in the IAMs should be consistent with our understanding of the costs of coordinating $\mathrm{R} \& \mathrm{D}$ policies in polycentric governance regimes. The second difficulty with NETs and the standard model of directed technical change is that many NETs have no value except for their contribution to lower GHG concentrations. These are not substitutes for some other way of producing goods. While R\&D investment is required to bring NETs costs down, their use never becomes less dependent on the GHG price, as is the case with renewables replacing fossil fuels. The optimal price path for inducing the development and deployment of NETs may be different from the optimal price path for inducing a shift from fossil energy to renewables. It is probably not appropriate to assume, as is often done now, that a single economy-wide GHG price can induce both an optimal mitigation path and the optimal deployment of NETs.

To explore technological growth outcomes across IAMs, we adapted the methodology of Wilson et al. (2013) to illustrate the projected capacity growth of NETs for IAM scenarios limiting warming to $1.5^{\circ} \mathrm{C}$ by 2100 . Assuming a logistic saturation pathway for all new technologies, Wilson et al. looked for regularities in the relationship between the extent of saturation (k) and the time (t) it takes to achieve (Wilson et al., 2013). The authors compare the historical transition to new energy technologies to the modeled energy technology transitions in IAMs. We apply the same method to NET technologies in IAMs, using data from three major model comparison scenarios included in the IAMC database, SSPX-1.9 (Rogelj et al., 2018), ADVANCE (Luderer et al., 2018), and CD-Links (McCollum et al., 2018).

Here, the $k$-value for each technology was calculated as follows:

$$
k=C_{\max }-C_{2005}
$$

Where: $C_{2005}=$ the carbon sequestration capacity in 2005; and $C_{\text {max }}=$ the maximum carbon sequestration capacity reached between 2005 and 2100, both in $\mathrm{GtCO}_{2} / \mathrm{yr}$. This is consistent with the way "cumulative capacity" for energy technologies is calculated in the $1.5^{\circ} \mathrm{C}$ database and creates an analogous metric for carbon sequestration technologies to the energy generation metric in Wilson et al. We calculate $\Delta \mathrm{t}$ as the elapsed time in years between the capacity reaching $\mathrm{C}_{2005}+0.1 k$ and $\mathrm{C}_{2005}+0.9 k$.

The $k$-values were then normalized by cumulative $\mathrm{CO}_{2}$ emissions from 2016 until net-zero emissions $\left(\mathrm{GtCO}_{2}\right)$, which drives the need for NETs deployment given a temperature or radiative forcing target. The results are overlaid in Figure 4 with the Wilson results (translated downwards in log-space) to illustrate how IAM results regarding NETs scale-up compare to those for energy technologies in IAMs and for historical energy technology transitions. Model output from $1.5^{\circ} \mathrm{C}$ compliant scenarios generally project technological growth for new NETs technologies more conservatively than historical energy system trends might suggest. This is broadly consistent with the findings that Wilson reported for the historical and projected future

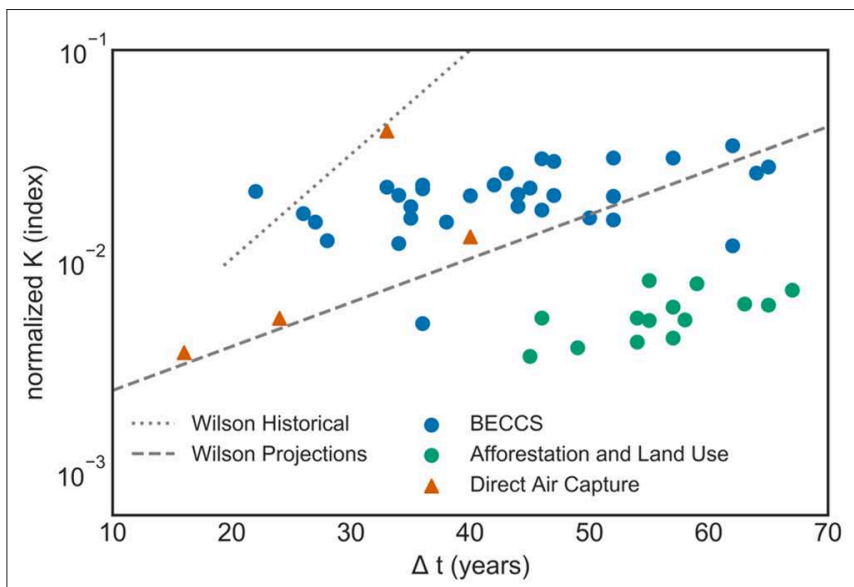

FIGURE 4 | Assumed future capacity growth of negative emissions for IAM scenarios limiting warming to $1.5^{\circ} \mathrm{C}$ by 2100 . The "historical" dotted line reflects the diffusion of six energy technologies globally found by Wilson et al. The "projected" dashed line reflects Wilson et al.'s MESSAGE-IAMF projections for Core Regions. Both overlays are translated downwards in log-space.

transitions in the energy sector. The scaleup rate and extent of some NETs with large resource demands and side effects (e.g., BECCS) is limited by land use constraints, and even then may be parameterized overly optimistically and/or limited by social factors including perceptions and concerns over equity (Iyer et al., 2015; Moreira et al., 2016). At the same time, there is a risk that NETs with large potential for technological breakthrough (e.g., DAC) and/or co-benefits (e.g., AW) may not be effectively modeled in IAMs. In particular, technologies with a greater degree of modularity (e.g., DAC processes capable of using lowtemperature waste heat) may have more rapid scale-up potential than "bulkier" technologies requiring more intensive investments in physical plants, supply chains, and pipeline networks (e.g., BECCS), especially in the initial phase (Wilson, 2012; Broehm et al., 2015; Realmonte et al., 2019). It seems clear from Figure 4 that there is wide disagreement among the current models about the scalability of NETs technologies. For BECCS, the time required to achieve a similar level of diffusion varies from 20 years to as long as 65 years.

\section{RECOMMENDATION \#3: WE NEED TO CONSIDER THE TRADEOFFS BETWEEN NETS AND SUSTAINABLE DEVELOPMENT GOALS}

Mitigation via emissions abatement and NETs directly contribute to climate action, one of the United Nation's Sustainable Development Goals (SDGs) (von Stechow et al., 2016). SDGs are target areas that the UN has laid out to help guide policy decisions in international development. While existing Nationally Determined Contribution pledges for meeting commitments under the Paris Accord are synergistic with some SDGs (e.g., Good Health and Well-Being from reduced fossil fuel combustion emissions), they may have trade-offs with 


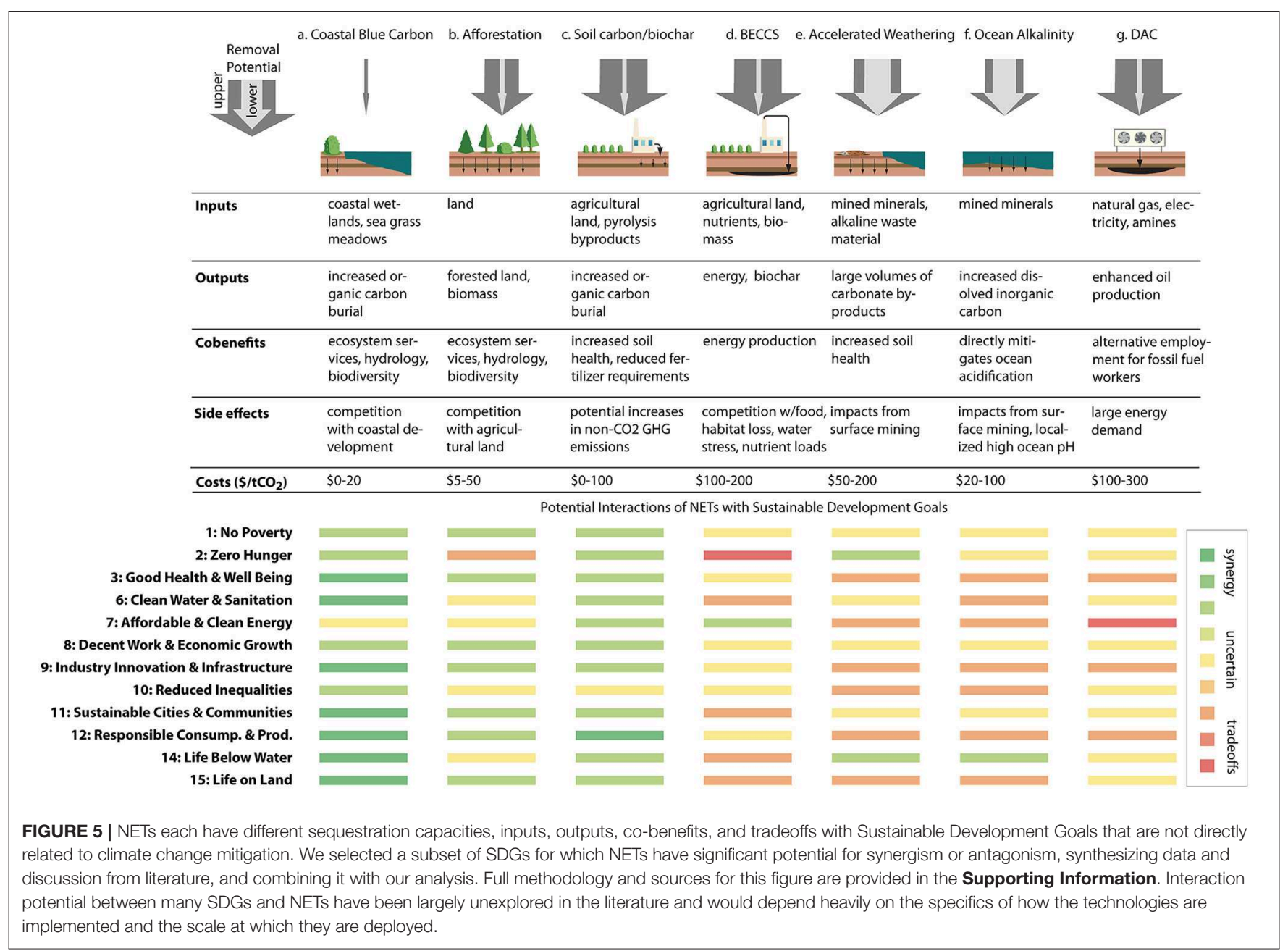

others (e.g., food and energy security) (Smith et al., 2019). The magnitude and sign of these interaction effects can differ by geographic region (Iyer et al., 2018). The scales at which IAMs project future NETs deployment only magnifies these potential tradeoffs. Nonetheless, IAMs have already proven to be a valuable tool for analyzing tradeoffs between BECCS, $\mathrm{AF}$ and other mitigation activities along the dimensions of food/energy security and biodiversity preservation, as well as policy instruments used to incentivize them (Calvin et al., 2014). The use of alternative NETs will likely pose new tradeoffs and potentially ameliorate others, and it is critical for these to be considered in IAM scenario design. Figure 5 summarizes potential impacts of candidate NETs in terms of their negative emissions potential, costs, side effects, co-benefits, and interaction potential with SDGs, synthesizing data and discussion from literature, and combining it with our own analysis. The full methodology and sources behind this figure are documented in the Supporting Information. NETs that restore or enhance natural processes tend to have greater synergy with SDGs but have scaling limitations and/or reversibility risks if the stored organic carbon is reoxidized. NETs that require the conversion of productive agricultural lands to either forest or bioenergy production (i.e., afforestation and BECCS) pose tradeoffs with the SDGs of poverty and hunger elimination; especially at the scales envisaged by most IAM projections. More "engineered" NETs which sequester $\mathrm{CO}_{2}$ in the subsurface or stable chemical compounds are more uncertain in terms of SDG interactions, depend heavily on implementation, and could provide co-benefits in one location and tradeoffs in another. As modeling teams begin to incorporate a fuller portfolio of NETs into IAMs, careful consideration should be given to these dimensions when designing scenarios, imposing realistic constraints on deployment, and communicating policy implications to stakeholders.

Even under optimistic assumptions of agricultural intensification and use of abandoned or marginal land for bioenergy production, meeting competing land demands of climate mitigation, food and energy security, and biodiversity preservation will be challenging (Canadell and Schulze, 2014). Although projections differ by model and scenario exactly where biomass production and AR activities would occur under aggressive global climate mitigation efforts, most model scenarios project large deployments of NETs in the developing world, which is responsible for only a small fraction 
of cumulative anthropogenic emissions to date. This poses obvious tradeoffs with SDG 10: Reduced Inequalities. Figure 6 shows downscaled results for second-generation biofuels production in 2100 in an RCP2.6 scenario generated using GCAM, which shows large impacts on sub-Saharan Africa and portions of the northern hemisphere that are currently not major agricultural regions but could be as the planet warms (Calvin et al., 2019).

Other models anticipate similar impacts in South America, with large portions of the Brazilian cerrado/Amazon being converted to intensive bioenergy feedstock production in aggressive mitigation scenarios (Hurtt et al., 2018). Figure 7 summarizes land-use impacts of afforestation and bioenergy production for $1.5^{\circ} \mathrm{C}$ scenarios, aggregated by five major geopolitical regions reported in the $1.5^{\circ} \mathrm{C}$ database, as well as globally. The median projection for global land area devoted to bioenergy in 2100 (with and without CCS) is $364 \mathrm{Mha}$, constituting approximately $3 \%$ of total global land area, and nearly $20 \%$ of current global cropland area (1,870 Mha) (Thenkabail et al., 2012; Teluguntla et al., 2015). Land use impacts of afforestation are projected to be much larger, with a median of $7 \%$ of global land area by 2100 , and much of this taking place in the developing world. These large scaleups are projected to be delayed to late-century in all regions as evidenced by the difference in deployment between 2030 and 2100 results. As in Figure 1, these results are driven largely by the underlying model architectures and scenario designs, for which the objective functions are based on economic cost minimization and/or market equilibrium. Externalities such as environmental damages not directly related to climate (e.g., biodiversity loss, water quality degradation), and other considerations such as inequality and inequity are generally not included in the formulations.

\section{HISTORICAL CONTEXT AND FUTURE DIRECTIONS}

Existing IAM scenarios rely heavily on land-based approaches (BECCS and AR) to achieve warming targets largely because of historical artifacts associated with the way these models were developed. Most IAMs were developed around energy and emissions modeling with land-use change models added to include the role of bioenergy and forestry. Under stringent emissions constraints, the models suggested pathways using these land-based approaches (Wise et al., 2009). Other dedicated NETs such as DAC or AW have not been widely included because the historical development paths did not have an obvious place for their inclusion. The results of our analysis suggest that the integrated assessment modeling community should consider incorporating a broader portfolio of NETs into existing model structures. Doing so would provide valuable information for a range of stakeholders and policymakers. We suggest that the IAM community evaluate the extent to which this highlights opportunities for more limited near-term deployment of potential alternative NETs, as opposed to presuming future large-scale deployment of more uncertain technologies. In particular, modelers should consider potential co-benefits and overlaps with other SDGs in conjunction with other aggressive near-term mitigation efforts. This would reduce risks associated

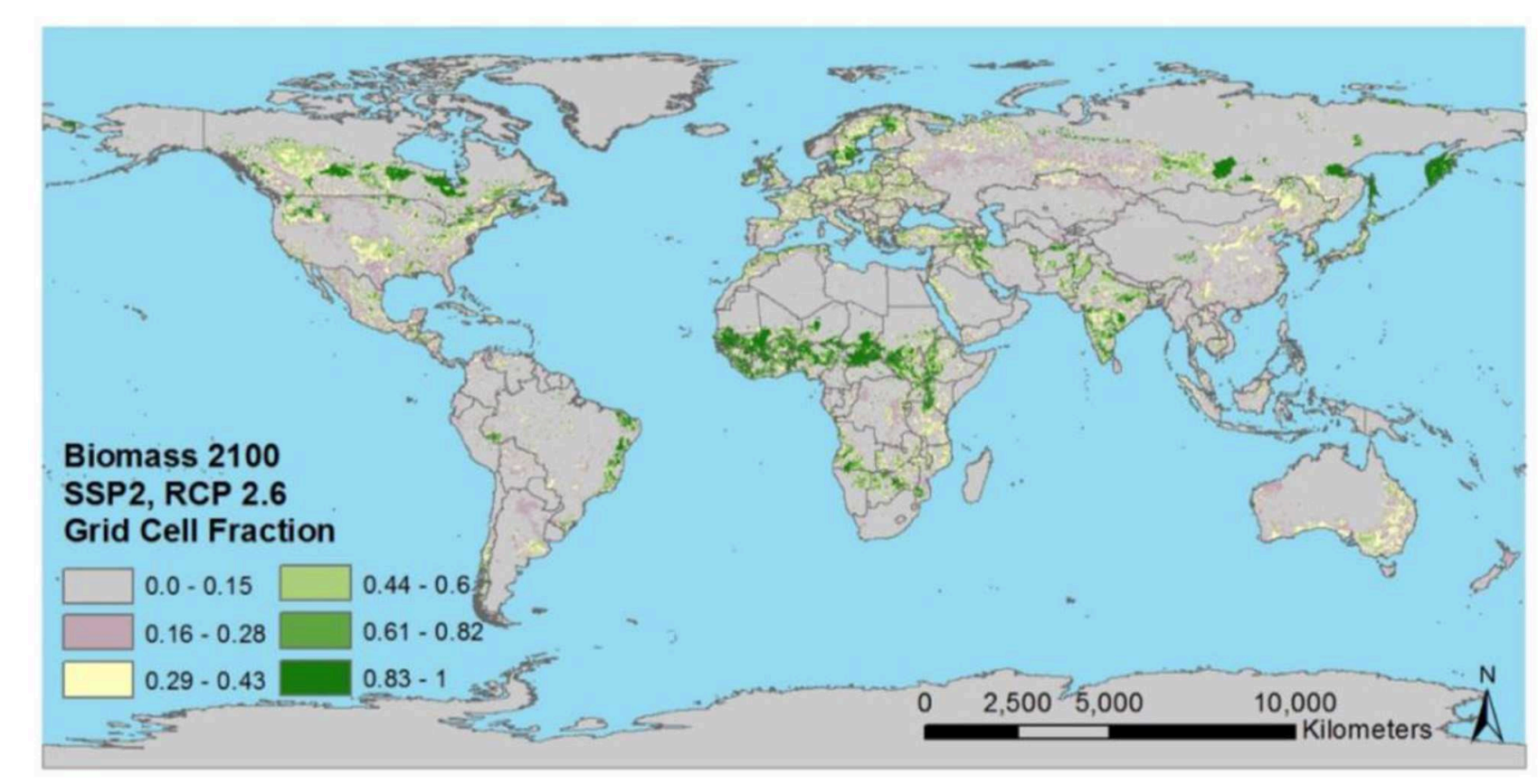

FIGURE 6 | World map showing projected fraction of land area devoted to dedicated bioenergy crops in a scenario consistent with limiting warming to $2^{\circ} \mathrm{C}(\mathrm{RCP} 2.6)$, using downscaled data from GCAM. Data source: Calvin et al. (2019). 


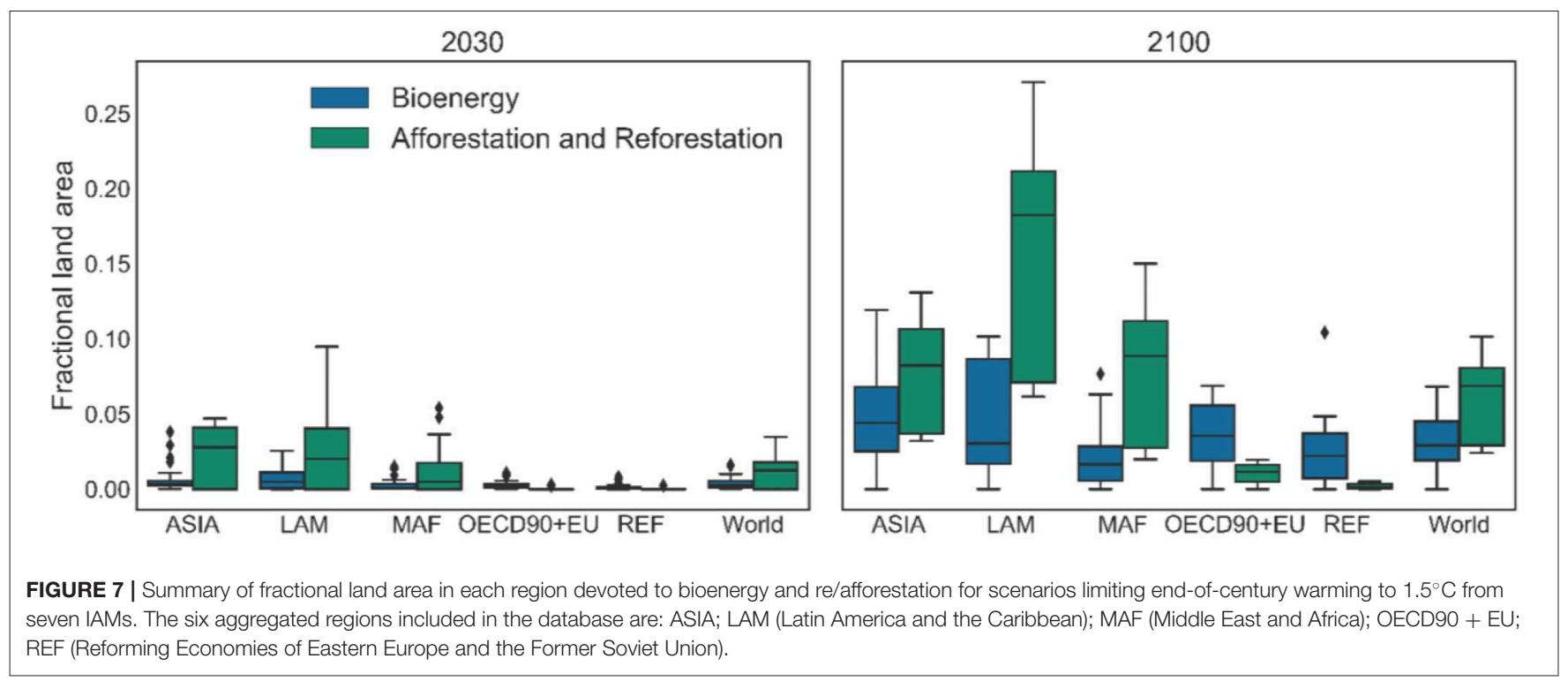

with irreversible climate change by minimizing or eliminating carbon budget overshoot.

IAMs were developed as one of a suite of tools to assess potential coordinated international policy responses to climate change. They allow assessment of implications of and sensitivity to a wide range of parameters (e.g., technological rates of change and social discount rates) at global scales, and complement regional and local-scale economic and energy systems models which help inform implementation of the top-line policy requirements found by IAMs with more granularity. Clearly, IAMs and their treatment of NETs needs to be improved and complemented with other analytical approaches if these models are to continue to provide useful insights. Results projecting large-scale future deployment of NETs should be communicated to and interpreted by policymakers and other stakeholders as warnings of the potential impacts of the NETs themselves, rather than prescriptive licenses to delay taking action and attempt reverse the damage later. An interdisciplinary effort by economists, environmental scientists, engineers, political scientists, and ethicists will be required to improve IAMs and the policies they are meant to inform if we are to avoid the worst damages of climate change, as well as from attempts to reverse it with a speculative future NETs "moonshot."

\section{REFERENCES}

Abotalib, M., Zhao, F., and Clarens, A. (2016). Deployment of a geographical information system life cycle assessment integrated framework for exploring the opportunities and challenges of enhanced oil recovery using industrial $\mathrm{CO}_{2}$ supply in the United States. ACS Sustain. Chem. Eng. 4, 4743-4751. doi: 10.1021/acssuschemeng. $6 \mathrm{~b} 00957$

Acemoglu, D., Aghion, P., Bursztyn, L., and Hemous, D. (2012). The environment and directed technical change. Am. Econ. Rev. 102, 131-166. doi: $10.2139 /$ ssrn. 1668575

\section{AUTHOR CONTRIBUTIONS}

The authors worked collectively to design the review. JF performed the majority of the data analysis with guidance from $\mathrm{HM}$ and AC. All authors contributed to the writing of the manuscript. AC revised the draft. All authors approved the submitted version.

\section{ACKNOWLEDGMENTS}

The authors wish to acknowledge support from the University of Virginia Vice President for Research-3 Cavaliers Program, the University of Virginia Environmental Resilience Institute, the US Department of Education-Graduate Assistance in Areas of National Need Program, and the Global Technology Strategy Program. We'd like to thank C. Vernon for providing downscaled map data for bioenergy production.

\section{SUPPLEMENTARY MATERIAL}

The Supplementary Material for this article can be found online at: https://www.frontiersin.org/articles/10.3389/fclim. 2019.00011/full\#supplementary-material

Acemoglu, D., Akcigit, U., Hanley, D., and Kerr, W. R. (2014). Transition to clean technology. J. Polit. Econ. 124, 52-104. doi: 10.3386/w20743

Barbier, E. B., Hacker, S. D., Kennedy, C., Koch, E. W., Stier, A. C., and Silliman, B. R. (2011). The value of estuarine and coastal ecosystem services. Ecol. Monogr. 81, 169-193. doi: 10.1890/10-1510.1

Bastin, J.-F., Finegold, Y., Garcia, C., Mollicone, D., Rezende, M., Routh, D., et al. (2019). The global tree restoration potential. Science. 365, 76-79. doi: $10.1126 /$ science.aax0848

Beerling, D. J., Leake, J. R., Long, S. P., Scholes, J. D., Ton, J., Nelson, P. N., et al. (2018). Farming with crops and rocks to address global climate, food and soil security. Nat. Plants 4, 138-147. doi: 10.1038/s41477-018-0108-y 
BP (2019). BP Statistical Review of World Energy. Available online at: https://www. bp.com/en/global/corporate/energy-economics/statistical-review-of-worldenergy.html (accessed October 16, 2019).

Broehm, M., Strefler, J., and Bauer, N. (2015). Techno-economic review of direct air capture systems for large scale mitigation of atmospheric $\mathrm{CO}_{2}$. SSRN Electron. J. doi: $10.2139 / \mathrm{ssrn} .2665702$

California Department of Forestry and Fire Protection, California Natural Resources Agency, and California Environmental Protection Agency (2018). California Forest Carbon Plan: Managing Our Forest Landscapes in a Changing Climate. Sacramento, CA. Available online at: http://resources.ca.gov/wpcontent/uploads/2018/05/California-Forest-Carbon- Plan- Final-Draft-forPublic-Release-May-2018.pdf (accessed October 14, 2019).

Calvin, K., Patel, P., Clarke, L., Asrar, G., Bond-Lamberty, B., Cui, R. Y., et al. (2019). GCAM v5.1: representing the linkages between energy, water, land, climate, and economic systems. Geosci. Model Dev. 12, 677-698. doi: 10.5194/gmd-12-677-2019

Calvin, K., Wise, M., Kyle, P., Patel, P., Clarke, L., and Edmonds, J. (2014). Tradeoffs of different land and bioenergy policies on the path to achieving climate targets. Clim. Chang. 123, 691-704. doi: 10.1007/s10584-013-0897-y

Canadell, J. G., and Schulze, E. D. (2014). Global potential of biospheric carbon management for climate mitigation. Nat. Commun. 5:5282. doi: $10.1038 /$ ncomms6282

Chen, C., and Tavoni, M. (2013). Direct air capture of $\mathrm{CO}_{2}$ and climate stabilization: a model based assessment. Clim. Chang. 118, 59-72. doi: 10.1007/s10584-013-0714-7

Clarke, L., Sokka, L., Jiang, K., Akimoto, K., Babiker, M., Blanford, G., et al. (2014). Assessing Transformation Pathways Coordinating Lead Authors: Chapter Science Assistant. Available online at: https://www.ipcc.ch/report/ar5/wg3/assessingtransformation-pathways/ (accessed May 30, 2019).

Climate Action Tracker (2019). Warming Projections Global Update. Available online at: https://climateactiontracker.org/documents/644/CAT_2019-09-19_ BriefingUNSG_WarmingProjectionsGlobalUpdate_Sept2019.pdf (accessed October 14, 2019).

Coady, D., Parry, I., Le, N. P., and Shang, B. (2019). Global Fossil Fuel Subsidies Remain Large: An Update Based on Country-Level Estimates. IMF Work. Pap. Available online at: https://www.imf.org/en/Publications/WP/Issues/2019/ 05/02/Global-Fossil-Fuel-Subsidies-Remain-Large-An-Update-Based-onCountry-Level-Estimates- 46509 (accessed October 21, 2019).

Creutzig, F., Breyer, C., Hilaire, J., Minx, J., Peters, G., and Socolow, R. H. (2019). The mutual dependence of negative emission technologies and energy systems. Energy Environ. Sci. 12, 1805-1817. doi: 10.1039/C8EE 03682A

Daniel, K. D., Litterman, R. B., and Wagner, G. (2019). Declining $\mathrm{CO}_{2}$ price paths. Proc. Natl. Acad. Sci. U.S.A. 116, 20886-20891. doi: 10.1073/pnas.1817444116

Di Vittorio, A. V., Chini, L. P., Bond-Lamberty, B., Mao, J., Shi, X., Truesdale, J., et al. (2014). From land use to land cover: restoring the afforestation signal in a coupled integrated assessment-earth system model and the implications for CMIP5 RCP simulations. Biogeosciences 11, 6435-6450. doi: 10.5194/bg-11-6435-2014

Edenhofer, O., Giannousakis, A., Bauer, N., Kriegler, E., Strefler, J., and Popp, A. (2018). Between Scylla and Charybdis: delayed mitigation narrows the passage between large-scale CDR and high costs. Environ. Res. Lett. 13:044015. doi: 10.1088/1748-9326/aab2ba

Furukawa, K., Wolanski, E., and Mueller, H. (1997). Currents and sediment transport in Mangrove forests. Estuar. Coast. Shelf Sci. 44, 301-310. doi: 10.1006/ecss.1996.0120

Fuss, S., Lamb, W. F., Callaghan, M. W., Hilaire, J., Creutzig, F., Amann, T., et al. (2018). Negative emissions-part 2: costs, potentials and side effects. Environ. Res. Lett. 13:063002. doi: 10.1088/1748-9326/aabf9f

Gacia, E., and Duarte, C. M. (2001). Sediment retention by a Mediterranean Posidonia oceanica meadow: the balance between deposition and resuspension. Estuar. Coast. Shelf Sci. 52, 505-514. doi: 10.1006/ecss.2000. 0753

Gambhir, A., Butnar, I., Li, P.-H., Smith, P., Strachan, N., Gambhir, A., et al. (2019). A review of criticisms of integrated assessment models and proposed approaches to address these, through the lens of BECCS. Energies 12:1747. doi: 10.3390/en12091747
Gattuso, J.-P., Magnan, A. K., Bopp, L., Cheung, W. W. L., Duarte, C. M., Hinkel, J., et al. (2018). Ocean solutions to address climate change and its effects on marine ecosystems. Front. Mar. Sci. 5:337. doi: 10.3389/fmars.2018.00337

GESAMP (2019). "High level review of a wide range of proposed marine geoengineering techniques," in IMO/FAO/UNESCOIOC/UNIDO/WMO/IAEA/UN/UN Environment/UNDP/ISA Joint Group of Experts on the Scientific Aspects of Marine Environmental Protection. Rep. Stud. GESAMP, eds P. W. Boyd and C. M. G. Vivian, 144.

Griscom, B. W., Adams, J., Ellis, P. W., Houghton, R. A., Lomax, G., Miteva, D. A., et al. (2017). Natural climate solutions. Proc. Natl. Acad. Sci. U.S.A. 114, 11645-11650. doi: 10.1073/pnas.1710465114

Grubler, A., Wilson, C., Bento, N., Boza-Kiss, B., Krey, V., McCollum, D. L., et al. (2018). A low energy demand scenario for meeting the $1.5^{\circ} \mathrm{C}$ target and sustainable development goals without negative emission technologies. Nat. Energy 3, 515-527. doi: 10.1038/s41560-018-0172-6

Haszeldine, R. S., Flude, S., Johnson, G., and Scott, V. (2018). Negative emissions technologies and carbon capture and storage to achieve the Paris Agreement commitments. Philos. Trans. R. Soc. A Math. Phys. Eng. Sci. 376:20160447. doi: 10.1098/rsta.2016.0447

He, S., and Mo, Z. (2019). "Reforestation projects at Pearl River Basin of Guangxi in China," in Forest Carbon Practices and Low Carbon Development in China, eds Z. Lu, X. Zhang, J. Ma, and C. Tang (Singapore: Springer), 91-127.

Holz, C., Siegel, L. S., Johnston, E., Jones, A. P., and Sterman, J. (2018). Ratcheting ambition to limit warming to $1.5^{\circ} \mathrm{C}$-trade-offs between emission reductions and carbon dioxide removal. Environ. Res. Lett. 13:64028. doi: 10.1088/1748-9326/aac0c1

Howarth, R. W., Santoro, R., and Ingraffea, A. (2011). Methane and the greenhouse-gas footprint of natural gas from shale formations. Clim. Chang. 106, 679-690. doi: 10.1007/s10584-011-0061-5

Huijgen, W. J. J., Witkamp, G. J., and Comans, R. N. J. (2005). Mineral $\mathrm{CO}_{2}$ sequestration by steel slag carbonation. Environ. Sci. Technol. 39, 9676-9682. doi: 10.1021/es050795f

Huppmann, D., Kriegler, E., Krey, V., Riahi, K., Rogelj, J., Rose, S. K., et al. (2018). IAMC $1.5^{\circ} \mathrm{C}$ Scenario Explorer and Data hosted by IIASA. International Institute for Applied Systems Analysis \& Integrated Assessment Modeling Consortium doi: 10.22022/SR15/08-2018.15429

Hurtt, G., Chini, L., Sahajpal, R., Frolking, S., Fisk, J., Bodirsky, B., et al. (2018). Harmonization of global land-use change and management for the period 850-2100. Geosci. Model Dev. Available online at: https://luh.umd.edu/faq. shtml

IPCC (2014). Climate Change 2014: Synthesis Report. Contribution of Working Groups I, II and III to the Fifth Assessment Report of the Intergovernmental Panel on Climate Change. Geneva: IPCC. Available online at: http://www.ipcc. ch (accessed February 8, 2019).

IPCC (2018). Global Warming of $1.5^{\circ} \mathrm{C}$ an IPCC Special Report on The Impacts of Global Warming of $1.5^{\circ} \mathrm{C}$ Above Pre-Industrial Levels And Related Global Greenhouse Gas Emission Pathways, in The Context Of Strengthening the Global Response to the Threat of Climate Change. Available online at: https://www.ipcc. ch/sr15/download/\#full (accessed December 17, 2018).

Iyer, G., Calvin, K., Clarke, L., Edmonds, J., Hultman, N., Hartin, C., et al. (2018). Implications of sustainable development considerations for comparability across nationally determined contributions. Nat. Clim. Change 8, 124-129. doi: 10.1038/s41558-017-0039-z

Iyer, G., Hultman, N., Eom, J., McJeon, H., Patel, P., and Clarke, L. (2015). Diffusion of low-carbon technologies and the feasibility of long-term climate targets. Technol. Forecast. Soc. Chang. 90, 103-118. doi: 10.1016/j.techfore.2013.08.025

Jobbágy, E. G., and Jackson, R. B. (2004). Groundwater use and salinization with grassland afforestration. Glob. Chang. Biol. 10, 1299-1312. doi: 10.1111/j.1365-2486.2004.00806.x

Kantola, I. B., Masters, M. D., Beerling, D. J., Long, S. P., and DeLucia, E. H. (2017). Potential of global croplands and bioenergy crops for climate change mitigation through deployment for enhanced weathering. Biol. Lett. 13:20160714. doi: 10.1098/rsbl.2016.0714

Kato, E., and Yamagata, Y. (2014). BECCS capability of dedicated bioenergy crops under a future land-use scenario targeting net negative carbon emissions. Earth's Futur. 2, 421-439. doi: 10.1002/2014EF000249 
Keith, D. W., Holmes, G., St Angelo, D., and Heidel, K. (2018). A process for capturing $\mathrm{CO}_{2}$ from the atmosphere. Joule 2, 1573-1594. doi: 10.1016/j.joule.2018.05.006

Keller, D. P., Lenton, A., Scott, V., Vaughan, N. E., Bauer, N., Ji, D., et al. (2018). The Carbon Dioxide Removal Model Intercomparison Project (CDRMIP): rationale and experimental protocol for CMIP6. Geosci. Model Dev. 11, 1133-1160. doi: 10.5194/gmd-11-1133-2018

Kohler, P., Hartmann, J., and Wolf-Gladrow, D. A. (2010). Geoengineering potential of artificially enhanced silicate weathering of olivine. Proc. Natl. Acad. Sci.U.S.A. 107, 20228-20233. doi: 10.1073/pnas.1000545107

Lawrence, B. M. G. (2019). Promises and perils of the Paris agreement. Science 364, 829-830. doi: 10.1126/science.aaw4602

Le Quéré, C., Andrew, R. M., Friedlingstein, P., Sitch, S., Hauck, J., Pongratz, J., et al. (2018). Global carbon budget 2018. Earth Syst. Sci. Data 10, 2141-2194. doi: 10.5194/essd-10-2141-2018

Lemoine, D., and Traeger, C. P. (2016). Economics of tipping the climate dominoes. Nat. Clim. Chang. 6, 514-519. doi: 10.1038/nclimate2902

Luderer, G., Vrontisi, Z., Bertram, C., Edelenbosch, O. Y., Pietzcker, R. C., Rogelj, J., et al. (2018). Residual fossil $\mathrm{CO}_{2}$ emissions in $1.5-2^{\circ} \mathrm{C}$ pathways. Nat. Clim. Chang. 8, 626-633. doi: 10.1038/s41558-018-0198-6

Mac Dowell, N., and Fajardy, M. (2017). Inefficient power generation as an optimal route to negative emissions via BECCS? Environ. Res. Lett. 12:045004. doi: 10.1088/1748-9326/aa67a5

Macreadie, P. I., Nielsen, D. A., Kelleway, J. J., Atwood, T. B., Seymour, J. R., Petrou, K., et al. (2017). Can we manage coastal ecosystems to sequester more blue carbon? Front. Ecol. Environ. 15:1484. doi: 10.1002/fee.1484

Marcucci, A., Kypreos, S., and Panos, E. (2017). The road to achieving the longterm Paris targets: energy transition and the role of direct air capture. Clim. Chang. 144, 181-193. doi: 10.1007/s10584-017-2051-8

Matter, J. M., Stute, M., Snaebjornsdottir, S. O., Oelkers, E. H., Gislason, S. R., Aradottir, E. S., et al. (2016). Rapid carbon mineralization for permanent disposal of anthropogenic carbon dioxide emissions. Science 352, 1312-1314. doi: $10.1126 /$ science.aad 8132

Mayor's Office of Recovery and Resiliency, New York City Economic Development Corporation, and Recovery, G. O. S. (2019). Lower Manhattan Climate Resiliance Study. New York, NY: Mayor's Office of Recovery and Resiliency (ORR) NYC Economic Development Corporation (EDC) Governor's Office of Storm Recovery.

McCollum, D. L., Zhou, W., Bertram, C., de Boer, H.-S., Bosetti, V., Busch, S., et al. (2018). Energy investment needs for fulfilling the Paris Agreement and achieving the Sustainable Development Goals. Nat. Energy 3, 589-599. doi: 10.1038/s41560-018-0179-z

McLeod, E., Chmura, G. L., Bouillon, S., Salm, R., Björk, M., Duarte, C. M., et al. (2011). A blueprint for blue carbon: toward an improved understanding of the role of vegetated coastal habitats in sequestering $\mathrm{CO}_{2}$. Front. Ecol. Environ. 9, 552-560. doi: 10.1890/110004

Mendez, F. J., and Losada, I. J. (2004). An empirical model to estimate the propagation of random breaking and nonbreaking waves over vegetation fields. Coast. Eng. 51, 103-118. doi: 10.1016/j.coastaleng.2003.11.003

Middleton, R. S., Clarens, A. F., Liu, X., Bielicki, J. M., and Levine, J. S. (2014). $\mathrm{CO}_{2}$ deserts: implications of existing $\mathrm{CO}_{2}$ supply limitations for carbon management. Environ. Sci. Technol. 48, 11713-11720. doi: 10.1021/es5022685

Minx, J. C., Lamb, W. F., Callaghan, M. W., Fuss, S., Hilaire, J., Creutzig, F., et al. (2018). Negative emissions-part 1: research landscape and synthesis. Environ. Res. Lett. 13:063001. doi: 10.1088/1748-9326/aabf9b

Moreira, J. R., Romeiro, V., Fuss, S., Kraxner, F., and Pacca, S. A. (2016). BECCS potential in Brazil: achieving negative emissions in ethanol and electricity production based on sugar cane bagasse and other residues. Appl. Energy 179, 55-63. doi: 10.1016/j.apenergy.2016.06.044

Muratori, M., Calvin, K., Wise, M., Kyle, P., and Edmonds, J. (2016). Global economic consequences of deploying bioenergy with carbon capture and storage (BECCS). Environ. Res. Lett. 11:095004. doi: 10.1088/1748-9326/11/9/095004

Nagelkerken, I., Blaber, S. J. M., Bouillon, S., Green, P., Haywood, M., Kirton, L. G., et al. (2008). The habitat function of mangroves for terrestrial and marine fauna: a review. Aquat. Bot. 89, 155-185. doi: 10.1016/j.aquabot.2007. 12.007
Nemet, G. F., Callaghan, M. W., Creutzig, F., Fuss, S., Hartmann, J., Hilaire, J., et al. (2018). Negative emissions - part 3: innovation and upscaling. Environ. Res. Lett. 13:063003. doi: 10.1088/1748-9326/aabff4

NRC (2015). Climate Intervention: Carbon Dioxide Removal and Reliable Sequestration. Washington, DC: The National Academies Press.

NRC (2018). Negative Emissions Technologies and Reliable Sequestration. Washington, DC: The National Academies Press.

Obersteiner, M., Bednar, J., Wagner, F., Gasser, T., Ciais, P., Forsell, N., et al. (2018). How to spend a dwindling greenhouse gas budget. Nat. Clim. Chang. 8, 7-10. doi: 10.1038/s41558-017-0045-1

Ornstein, L., Aleinov, I., and Rind, D. (2009). Irrigated afforestation of the Sahara and Australian outback to end global warming. Clim. Chang. 97, 409-437. doi: 10.1007/s10584-009-9626-y

Rau, G. H. (2018). The race to remove $\mathrm{CO}_{2}$ needs more contestants. Nat. Clim. Chang. 9:256. doi: 10.1038/s41558-019-0445-5

Realmonte, G., Drouet, L., Gambhir, A., Glynn, J., Hawkes, A., Köberle, A. C., et al. (2019). An inter-model assessment of the role of direct air capture in deep mitigation pathways. Nat. Commun. 10:3277. doi: 10.1038/s41467-019-10842-5

Reister, D. B., and Edmonds, J. A. (1977). "A general equilibrium two-sector energy demand model," in Modeling Energy-Economy Interac-tions: Five Approaches. Washington, DC: Resources for the Future.

Rogelj, J., Huppmann, D., Krey, V., Riahi, K., Clarke, L., Gidden, M., et al. (2019). A new scenario logic for the Paris Agreement long-term temperature goal. Nature 573, 357-363. doi: 10.1038/s41586-019-1541-4

Rogelj, J., Popp, A., Calvin, K. V., Luderer, G., Emmerling, J., Gernaat, D., et al. (2018). Scenarios towards limiting global mean temperature increase below 1.5 ${ }^{\circ}$ C. Nat. Clim. Chang. 8, 325-332. doi: 10.1038/s41558-018-0091-3

Rogelj, J., Shindell, D., Jiang, K., Fifita, S., Forster, P., Ginzburg, V., et al. (in press). "Mitigation pathways compatible with $1.5^{\circ} \mathrm{C}$ in the context of sustainable development," in Global Warming of $1.5^{\circ} \mathrm{C}$. An IPCC Special Report on the Impacts of Global Warming of $1.5^{\circ} \mathrm{C}$ Above Pre-Industrial Levels and Related Global Greenhouse Gas Emission Pathways, in the Context of Strengthening the Global Response to the Threat of Climate Change, Sustainable Development, and Efforts to Eradicate Poverty, eds V. Masson-Delmotte, P. Zhai, H.-O. Pörtner, D. Roberts, J. Skea, P. R. Shukla, A. Pirani, W. Moufouma-Okia, C. Péan, R. Pidcock, S. Connors, J. B. R. Matthews, Y. Chen, X. Zhou, M. I. Gomis, E. Lonnoy, T. Maycock, M. Tignor, and T. Waterfield.

Sanderman, J., Hengl, T., and Fiske, G. J. (2017). Soil carbon debt of 12,000 years of human land use. Proc. Natl. Acad. Sci. U.S.A. 114, 9575-9580. doi: 10.1073/pnas.1706103114

Schleussner, C.-F., Rogelj, J., Schaeffer, M., Lissner, T., Licker, R., Fischer, E. M., et al. (2016). Science and policy characteristics of the Paris Agreement temperature goal. Nat. Clim. Chang. 6, 827-835. doi: 10.1038/nclimate3096

Sen, I. S., and Peucker-Ehrenbrink, B. (2012). Anthropogenic disturbance of element cycles at the earth's surface. Environ. Sci. Technol. 46, 8601-8609. doi: $10.1021 / \mathrm{es} 301261 \mathrm{x}$

Smith, P., Adams, J., Beerling, D. J., Beringer, T., Calvin, K. V., Fuss, S., et al. (2019). Impacts of land-based greenhouse gas removal options on ecosystem services and the United Nations sustainable development goals. Annu. Rev. Environ. Resour. 44, 1-32. doi: 10.1146/annurev-environ-101718-033129

Smith, P., Davis, S. J., Creutzig, F., Fuss, S., Minx, J., Gabrielle, B., et al. (2016). Biophysical and economic limits to negative $\mathrm{CO}_{2}$ emissions. Nat. Clim. Chang. 6, 42-50. doi: 10.1038/nclimate2870

Steffen, W., Rockström, J., Richardson, K., Lenton, T. M., Folke, C., Liverman, D., et al. (2018). Trajectories of the earth system in the anthropocene. Proc. Natl. Acad. Sci. U.S.A. 115, 8252-8259. doi: 10.1073/pnas.1810141115

Strefler, J., Amann, T., Bauer, N., Kriegler, E., and Hartmann, J. (2018). Potential and costs of carbon dioxide removal by enhanced weathering of rocks. Environ. Res. Lett. 13:034010. doi: 10.1088/1748-9326/ aaa9c4

Tavoni, M., and Socolow, R. (2013). Modeling meets science and technology: an introduction to a special issue on negative emissions. Clim. Chang. 118, 1-14. doi: 10.1007/s10584-013-0757-9

Taylor, L. L., Quirk, J., Thorley, R. M. S., Kharecha, P. A., Hansen, J., Ridgwell, A., et al. (2016). Enhanced weathering strategies for stabilizing climate and averting ocean acidification. Nat. Clim. Chang. 6, 402-406. doi: 10.1038/nclimate 2882 
Teluguntla, P., Thenkabail, P. S., Xiong, J., Gumma, M. K., Giri, C., Cristina, M., et al. (2015). "Global Cropland Area Database (GCAD) derived from remote sensing in support of food security in the twenty-first century: current achievements and future possibilities," in Land Resources: Monitoring, Modelling, and Mapping, Remote Sensing Handbook, Vol. 2, ed P. S. Thenkabail (Boca Raton, FL: Taylor \& Francis). Available online at: http://pubs.er.usgs.gov/ publication/70117684

Thenkabail, P. S., J.W., K., Ozdogan, M., Gumma, M. K., Congalton, R. G., et al. (2012). Assessing future risks to agricultural productivity, water resources and food security: how can remote sensing help? Photogramm. Eng. Remote Sensing $78,773-782$.

Tollefson, J. (2018). Can the world kick its fossil-fuel addiction fast enough? Nature 556, 422-425. doi: 10.1038/d41586-018-04931-6

UNFCCC and Conference of the Parties (COP) (2015). Paris Climate Change Conference-November 2015. (Paris: COP), 21.

United Nations Environment Programme (2018). Emissions Gap Report 2018. Available online at: https://www.unenvironment.org/resources/emissions-gapreport-2018 (accessed October 10, 2019).

van Vuuren, D. P., Stehfest, E., Gernaat, D. E. H. J., van den Berg, M., Bijl, D. L., de Boer, H. S., et al. (2018). Alternative pathways to the $1.5^{\circ} \mathrm{C}$ target reduce the need for negative emission technologies. Nat. Clim. Chang. 8, 391-397. doi: 10.1038/s41558-018-0119-8

Vaughan, N. E., and Gough, C. (2016). Expert assessment concludes negative emissions scenarios may not deliver. Environ. Res. Lett. 11:095003. doi: 10.1088/1748-9326/11/9/095003

von Stechow, C., Minx, J. C., Riahi, K., Jewell, J., McCollum, D. L., Callaghan, M. W., et al. (2016). $2^{\circ} \mathrm{C}$ and SDGs: united they stand, divided they fall? Environ. Res. Lett. 11:034022. doi: 10.1088/1748-9326/11/3/034022
Wilson, C. (2012). Up-scaling, formative phases, and learning in the historical diffusion of energy technologies. Energy Policy 50, 81-94. doi: 10.1016/j.enpol.2012.04.077

Wilson, C., Grubler, A., Bauer, N., Krey, V., and Riahi, K. (2013). Future capacity growth of energy technologies: are scenarios consistent with historical evidence? Clim. Chang. 118, 381-395. doi: 10.1007/s10584-012-0618-y

Wise, M., Calvin, K., Thomson, A., Clarke, L., Bond-Lamberty, B., Sands, R., et al. (2009). Implications of limiting $\mathrm{CO}_{2}$ concentrations for land use and energy. Science 324, 1183-6. doi: 10.1126/science.1168475

Yang, S. L., Shi, B. W., Bouma, T. J., Ysebaert, T., and Luo, X. X. (2012). Wave attenuation at a salt marsh margin: a case study of an exposed coast on the Yangtze Estuary. Estuaries Coasts 35, 169-182. doi: 10.1007/s12237-011-9424-4

Zickfeld, K., MacDougall, A. H., and Matthews, H. D. (2016). On the proportionality between global temperature change and cumulative $\mathrm{CO}_{2}$ emissions during periods of net negative $\mathrm{CO}_{2}$ emissions. Environ. Res. Lett. 11:055006. doi: 10.1088/1748-9326/11/5/055006

Conflict of Interest: The authors declare that the research was conducted in the absence of any commercial or financial relationships that could be construed as a potential conflict of interest.

Copyright () 2019 Fuhrman, McJeon, Doney, Shobe and Clarens. This is an openaccess article distributed under the terms of the Creative Commons Attribution License (CC BY). The use, distribution or reproduction in other forums is permitted, provided the original author(s) and the copyright owner(s) are credited and that the original publication in this journal is cited, in accordance with accepted academic practice. No use, distribution or reproduction is permitted which does not comply with these terms. 